\title{
The Efficacy of Radiofrequency Ablation for Pain Management in Patients with Pre-Existing Hardware at the Site of Ablation
}

\author{
Alaa Abd-Elsayed · Meghan Hughes · Emily Narel · Michael D. Loebertman
}

Received: July 29, 2020 / Accepted: September 23, 2020 / Published online: October 8, 2020

(C) The Author(s) 2020

\begin{abstract}
Introduction: Radiofrequency ablation (RFA) is an interventional procedure that provides pain relief by using thermal energy to disrupt peripheral nerves carrying nociceptive signals back to the central nervous system. In the past, having implantable hardware at the planned site of RFA was considered to confer increased risk of adverse outcomes given the theoretical risk of heating of the hardware components. The present study examines patient outcomes to determine whether the efficacy of RFA was affected by the presence of implanted hardware directly at the site.
\end{abstract}

Methods: This was a retrospective case-control study that included 52 patients who received RFA procedures in the presence of hardware at the site of RFA and a control group of 170 patients who received RFA procedures in the absence of hardware. Data were collected from electronic medical records entered into an Excel sheet and then analyzed using SPSS version 22 . Outcomes tested included post procedure pain scores, percent, and duration of improvement, if any.

Results: We found no statistically significant difference in measured outcomes between either group.

Conclusions: This study provides some evidence in support of the theory that RFA procedures performed on patients with pre-existing hardware have similar efficacy when compared to their hardware-free counterparts.

Keywords: Chronic pain; Hardware; Pain; Radiofrequency ablation

\footnotetext{
A. Abd-Elsayed $(\bowtie)$

Department of Anesthesiology, School of Medicine and Public Health, University of Wisconsin, Madison, USA

e-mail: alaaawny@hotmail.com

M. Hughes · E. Narel · M. D. Loebertman School of Medicine and Public Health, University of Wisconsin, Madison, USA
} 


\section{Key Summary Points}

This study examines the efficacy of radiofrequency ablation, a commonly utilized pain management procedure, in the population of patients with implanted hardware such as joint replacements.

This study provides further guidance for treatment of pain that was not relieved by the use of implantable hardware.

Our hypothesis was that implantable hardware would have no effect on the efficacy of the radiofrequency ablation procedure.

We saw no difference in pain reduction or in relief duration between patients with and patients without implantable hardware near the site of radiofrequency ablation.

Through this study, we have demonstrated that radiofrequency ablation is as effective in patients who have been previously treated with implantable hardware as it is in those without such hardware.

Further study is needed with a larger number of patients, but this study serves as a starting point for further research into this procedure to provide pain relief to a patient population that is lacking safe and effective options.

\section{DIGITAL FEATURES}

This article is published with digital features, including [list digital features available e.g., a summary slide and video abstract], to facilitate understanding of the article. To view digital features for this article go to https://doi.org/10. 6084/m9.figshare.12988268.

\section{INTRODUCTION}

Chronic pain is an insidious and complex disease with considerable personal and economic impacts [1]. Although it is typically considered a presentation secondary to an ongoing disease, such as cancer, or the result of a work- or liferelated trauma [2], it is also a disease state in and of itself with its own pathology, genetic factors, and medical definition $[3,4]$.

"The Global Burden of Disease Study 2016 reaffirmed that the high prominence of pain and pain-related diseases is the leading cause of disability and disease burden globally [5]." "Measuring years lived with disability; low back and neck pain have consistently been the leading causes of disability internationally, with other chronic pain conditions featuring prominently in the top 10 causes of disability [5]."

Back pain is one of the most frequent reasons for visiting a physician in the United States and is the most common type of pain reported by Americans. "More than $\$ 100$ billion [6] is spent annually in the United States on low back pain, which is the leading cause of work-related disability and economic burden in the United States [7, 8]." Simply put, chronic pain has a significant effect on the economy and on the quality of life of those afflicted with it.

One of the most common causes of pain is facet joint degeneration [9-13]. "Radiofrequency neurotomy/ablation (RFN/RFA) of the medial branch nerves, the nerves which supply the facet joints, is a commonly used procedure and is one of the only proven efficacious interventional modalities for treating facet joint pain [14-16]." In a systematic review of randomized controlled trials (RCT) of RFA for chronic low back pain evidence was found to support RFA as an efficacious therapy for lumbar facet joint pain in five of six RCT analyzed [17]. In another meta-analysis looking at RFA in patients with chronic pain originating from the facet joints, RFA was found to be more efficacious than corticosteroid injections and found to result in better pain improvement for an entire year [18]. Specifically, "RFA is a procedure that may offer pain relief for patients without a known pathology [17]." 
RFA is often a treatment modality that is considered after surgical procedures that involved the placement of metallic hardware [19]. This is because patients who have undergone surgery often suffer from further joint degeneration secondary to the surgery itself [20], which leads to additional, subsequent pain that is best treated with RFA [19]. Unfortunately, "there is a theoretical risk involved with treating patients with existing spinal hardware with RFA, as the needle tip used for the procedure ends up in close proximity to this metal hardware [21]." The ultimate concern is that the metal hardware will serve as a heat sink, increasing the risk of thermal energy damage in the tissues surrounding it as well as drawing heat energy away from the intended site and thus reducing overall efficacy [21].

These risks remain theoretical due to a paucity of high-quality studies that directly explore the possibility that heat transfer does occur and that this occurrence, if it exists, has any impact on the safety and efficacy of the procedure.

At this time, the limited research that has been done has focused on the transfer of heat versus the efficacy of the procedure in these types of patients. Gazelka et al. [22], in a cadaver study, found that regardless if the RFA cannula was placed on or near the pedicle hardware, there was a significant increase in temperature of the hardware and that these "results suggested that pedicle screws could serve as a possible source of tissue heating and thermal injury during RFA [22]"; therefore, further precautions should be taken when performing this procedure on patients who had existing hardware at the site of the RFA procedure [22]. Lamer et al. [19] looked directly at patients who had existing spinal hardware. The results of their study aligned with those found by Gazelka et al. That is, temperature increases were seen in $60 \%$ of pedicle screws [19] with warnings that "a practitioner should weigh the risks and benefits of lesioning the medial branch nerve at a level adjacent to a pedicle screw to minimize the risk of heat energy transfer to the hardware and the surrounding tissue [19]." Klessinger [23] was one of the few to look at safety and efficacy of lumbar RFN in the presence of pedicle screws via a retrospective practice audit, which ultimately included 38 patients. Although they found strong evidence that the pedicle screws did 'sustain significantly increased temperatures,' no effect from heated metal devices was detected [22]. Even more, "patients reported no adverse effects or worsening pain. Therefore, despite the potential risk, RFA in the presence of pedicle screws appears to be a safe procedure [23]."

The purpose of our study was to specifically explore the efficacy of patients receiving RFA who also have existing hardware at the same site. We started at a place of accepting and anticipating that the hardware would be subjected to temperature increases, as this has now been validated by a minimum of three studies $[19,22,23]$. What we sought to elucidate was if this temperature increase had, in turn, any negative consequences on the outcomes of the procedure from an efficacy standpoint as there is continued theoretical concern that the dissipation of heat into the hardware can lead to a smaller lesion, which can reduce efficacy.

\section{METHODS}

This was a retrospective practice audit of a review of the charts of all RFA procedures done between January 2015 and January 2018. Ethics compliance was achieved by applying for exemption from the University of Wisconsin IRB board. The IRB board determined that the use of patient data met the criteria for federal exemption. This research was completed in compliance with the Helsinki Declaration of 1964. The total number of patients included in this review was 222 . One hundred and seventy of these RFA procedures did not have pre-existing hardware while 52 of these RFA procedures did have existing hardware at the direct site of the RFA. Of those without hardware, 51 were geniculate nerve RFA, two were femoral nerve RFA, 91 were lumbar medial branch RFA, 15 were lumbosacral medial branch RFA, two were sacral lateral branch RFA, and nine were cervical medial branch RFA. Of those with hardware, 16 were geniculate nerve RFA, 32 were lumbar medial branch RFA, three were lumbosacral medial branch RFA, and one was 
cervical medial branch RFA. RFA procedures in both groups were completed utilizing fluoroscopic guidance. All procedures were completed using cooled RFA at $60^{\circ}$ Celsius. The duration of ablation ranged from 150 to $180 \mathrm{~s}$ based on physician preference. Data collected included demographics, pre-procedure pain scores, postprocedure pain scores, percent improvement after procedure, and duration of improvement. Duration of improvement was defined as the time period in which the patient maintained $50 \%$ of total benefit from the procedure.

Data were collected in an Excel sheet and then were analyzed using SPSS 22. Data were presented as median and percentiles for numeric data and numbers for categorical data. Fisher's exact test was used for comparing categorical data between both groups; Wilcoxon signed-rank test was used for comparing preand post-procedure pain scores. A $p$ value of 0.05 or less was considered statistically significant.

\section{RESULTS}

This study included 222 patients who received RFA procedures. Fifty-two patients received RFA procedures with the presence of hardware at the site of RFA and 170 patients received RFA procedures with the absence of hardware at the site of RFA.

Of the patients with existing hardware, there was a relatively even split between male and female patients (27 vs. 25, respectively). This was less so in the hardware-absent group, where $63.5 \%$ (108) of the patients were women (Table 1). Over $95 \%$ of all study patients were Caucasian, likely a reflection of the region in which the study took place (Wisconsin, USA) more than anything else (Table 1).

Perhaps most notably, there was a significant difference ( $p$ value 0.00 ) between the ages of these two groups. The median age of the hardware-present group was 64 years while the median age of the hardware-absent group was 54 years (Table 1 ).

Table 1 Patients' demographics

\begin{tabular}{|c|c|c|c|c|c|c|c|}
\hline & \multicolumn{2}{|l|}{ Sex } & \multicolumn{3}{|l|}{ Race } & \multicolumn{2}{|l|}{ Age } \\
\hline & Male & $\overline{\text { Female }}$ & Caucasian & African American & Other & $\begin{array}{l}\text { Median } \\
\text { (25th-75th percentile) }\end{array}$ & $p$ value \\
\hline Hardware present & 27 & 25 & 51 & 0 & 1 & $64(55-74)$ & $0.00^{*}$ \\
\hline$N=52$ & $51.9 \%$ & $48.1 \%$ & $98.1 \%$ & $0.0 \%$ & $1.9 \%$ & - & \\
\hline Hardware absent & 62 & 108 & 166 & 3 & 1 & $54(44-64)$ & - \\
\hline$N=170$ & $36.5 \%$ & $63.5 \%$ & $97.6 \%$ & $1.8 \%$ & $0.6 \%$ & - & \\
\hline
\end{tabular}

* Significant difference in age between both groups 
Table 2 Comparison of outcome measures between both groups

\begin{tabular}{llll}
\hline & $\begin{array}{l}\text { Hardware present } \\
\text { Median (25th-75th percentile) }\end{array}$ & $\begin{array}{l}\text { Hardware absent } \\
\text { Median (25th-75th percentile) }\end{array}$ & $\boldsymbol{p}$ value \\
\hline Pre-procedure pain score & $7(6-8)$ & $7(5-8)$ & 0.612 \\
Post-procedure pain score & $3(1-5)$ & $3(1-5)$ & 0.749 \\
Percent pain reduction & $50(17-83)$ & $53(20-78)$ & 0.836 \\
Duration of pain reduction (days) & $92(2-168)$ & $90(3-197)$ & 0.559 \\
\hline
\end{tabular}

There was no significant difference in patients with or without hardware in response to their RFA procedures (Table 2). Pain reduction was seen in both groups with a median change of 3.0 ( $p$ value 0.749 ) based on a $0-10$ scale. Percent pain reduction averaged around $50 \%$ ( $p$ value 0.836 ) with an average duration of relief being roughly 90 days ( $p$ value 0.559 ). Most significant for our purposes is the simple fact that the RFA procedure produced similar results and relief irrespective of if the patient had existing hardware or not.

\section{DISCUSSION}

The global burden of pain-related disease is significant. The burden of chronic pain often outstrips that experienced by diabetes or asthma [24]. Furthermore, "studies consistently demonstrate that every measured dimension of health is worse when chronic pain is present than when it is not, and, in addition to this physical and emotional burden [24], the financial cost to society is huge: over $€ 200$ billion per annum in Europe, and $\$ 635$ billion per annum in the USA in 2008 [25]."

RFA is a commonly used technique to address multiple types of chronic pain. It is also one of the few interventional treatments that have proven efficacious over time to treat chronic pain, and studies have shown that a significantly greater improvement in pain symptoms, global perception of improvement, and quality of life were observed after 6 months in patients who received the treatment [26].

Despite the effectiveness of RFA as a therapy, there remains a paucity of literature studying the efficacy and safety of RFA procedures on patients with existing hardware; patients who, despite surgery, often still experience chronic and refractory pain. To date, there are two studies that have exclusively looked at the safety of performing RFA on patients with existing hardware $[19,22]$. Both of these studies did demonstrate that heat transfer occurred to pedicle screws but that this transfer did not, itself, present any contraindication for an RFA procedure. Rather, caution and logical risk mitigation was advised.

Klessinger [23] was the first doctor to perform a retrospective practice audit on the efficacy and safety of performing RFA on individuals with existing spinal hardware. His research bolstered the belief that although heating of existing metal hardware did occur, no effect, adverse or otherwise, was observed. There was no worsening of pain felt in the patients, no other adverse events, and no significant impact on efficacy. In the end, this study stated that "despite the potential risk, RFN in the presence of pedicle screws appears to be a safe procedure [23]."

Our study informs these existing works. Working under the assumption that existing metallic devices would experience temperature increases/heat dissipation, we focused on if the efficacy of the RFA procedure would be affected in any clinically significant way. Our results showed no statistically significant difference in the outcomes of patients with or without preexisting hardware. The amount of pain reduction as well as the duration of reduction was statistically similar in both groups. These outcomes indicate that RFA procedures performed in the growing population of patients with 
existing hardware are not associated with decreased efficacy as measured by pain reduction and pain relief duration.

The studies performed thus far lend credence to both the efficacy and safety of performing RFA procedures on patients with existing hardware. There is a clear need for further studies to be performed, as this population will only continue to grow.

As we have discussed, our research has provided further evidence to formally validate the perspective that providing RFA therapy to patients with existing hardware is not only safe but also effective. Although there is evidence to suggest that the stainless-steel and titanium screws commonly used in spinal surgery are capable of sustaining significant increases in temperature during RFA in the clinical setting $[19,22]$ no effect, negative or otherwise, was detected by practitioners or patients as a result of this reality.

\section{Limitations}

This was a retrospective study, and retrospective studies do not accommodate for all confounders. Additionally, the low number of patients in the hardware group affects the generalizability of this work.

\section{CONCLUSIONS}

Our study showed no difference in efficacy when RFA was performed in patients with hardware at site of procedure as compared to patients with no hardware.

\section{ACKNOWLEDGEMENTS}

Funding. No funding or sponsorship was received for this study or publication of this article.

Authorship. All named authors meet the International Committee of Medical Journal Editors (ICMJE) criteria for authorship for this article, take responsibility for the integrity of the work as a whole, and have given their approval for this version to be published. The authors would like to thank the participants of this study.

Disclosure. Alaa Abd-Elsayed is a consultant for Medtronic, StimWave, Avanos, and Sollis. Megan Hughes, Emily Narel, and Michael Loebertman have nothing to disclose.

Compliance with Ethic Guidelines. Ethics compliance was achieved by applying for exemption from the University of Wisconsin IRB board. The IRB board determined that the use of patient data met the criteria for federal exemption criteria. This research was completed in compliance with the Helsinki Declaration of 1964.

Data Availability. The datasets generated during and/or analyzed during the current study are not publicly available because the contents contain private health information.

Open Access. This article is licensed under a Creative Commons Attribution-NonCommercial 4.0 International License, which permits any non-commercial use, sharing, adaptation, distribution and reproduction in any medium or format, as long as you give appropriate credit to the original author(s) and the source, provide a link to the Creative Commons licence, and indicate if changes were made. The images or other third party material in this article are included in the article's Creative Commons licence, unless indicated otherwise in a credit line to the material. If material is not included in the article's Creative Commons licence and your intended use is not permitted by statutory regulation or exceeds the permitted use, you will need to obtain permission directly from the copyright holder. To view a copy of this licence, visit http://creativecommons.org/licenses/by$\mathrm{nc} / 4.0 /$. 


\section{REFERENCES}

1. Fayaz A, Croft P, Langford RM, Donaldson LJ, Jones GT. Prevalence of chronic pain in the UK: a systematic review and meta-analysis of population studies. BMJ Open. 2016;6(6):e010364.

2. Mills SEE, Nicolson KP, Smith BH. Chronic pain: a review of its epidemiology and associated factors in population-based studies. $\mathrm{Br} \mathrm{J}$ Anaesth. 2019;123(2):e273-e283283.

3. International Association for the Study of Pain, Task Force on Taxonomy, Merskey H, Bogduk N, editors. Classification of chronic pain: descriptions of chronic pain syndromes and definitions of pain terms. Seattle, WA: IASP Press; 1994.

4. Tracey I, Bushnell MC. How neuroimaging studies have challenged us to rethink: is chronic pain a disease? J Pain. 2009;10(11):1113-20.

5. GBD 2016 Disease and Injury Incidence and Prevalence Collaborators. Global, regional, and national incidence, prevalence, and years lived with disability for 328 diseases and injuries for 195 countries, 1990-2016: a systematic analysis for the Global Burden of Disease Study 2016. Lancet. 2017;390(10100):1211-59.

6. Katz JN. Lumbar disc disorders and low-back pain: socioeconomic factors and consequences. J Bone Jt Surg Am. 2006;88(Suppl 2):21-4.

7. Rubin DI. Epidemiology and risk factors for spine pain. Neurol Clin. 2007;25(2):353-71.

8. Murray CJ, Atkinson C, Bhalla K, Birbeck G, Burstein R, Chou D, et al. The state of US health, 1990-2010: burden of diseases, injuries, and risk factors. JAMA. 2013;310(6):591-608.

9. Deyo RA, Tsui-Wu YJ. Descriptive epidemiology of low-back pain and its related medical care in the United States. Spine (Phila Pa 1976). 1987;12(3): 264-8.

10. Schwarzer AC, Aprill CN, Derby R, Fortin J, Kine G, Bogduk N. Clinical features of patients with pain stemming from the lumbar zygapophysial joints. Is the lumbar facet syndrome a clinical entity? Spine (Phila Pa 1976). 1994;19(10):1132-7.

11. Schwarzer AC, Wang SC, Bogduk N, McNaught PJ, Laurent R. Prevalence and clinical features of lumbar zygapophysial joint pain: a study in an Australian population with chronic low back pain. Ann Rheum Dis. 1995;54(2):100-6.

12. Schwarzer AC, Aprill CN, Derby R, Fortin J, Kine G, Bogduk N. The relative contributions of the disc and zygapophyseal joint in chronic low back pain. Spine (Phila Pa 1976). 1994;19(7):801-6.

13. Bogduk N, Dreyfuss P, Govind J. A narrative review of lumbar medial branch neurotomy for the treatment of back pain. Pain Med. 2009;10(6):1035-45.

14. Dreyfuss P, Halbrook B, Pauza K, Joshi A, McLarty J, Bogduk N. Efficacy and validity of radiofrequency neurotomy for chronic lumbar zygapophysial joint pain. Spine (Phila Pa 1976). 2000;25(10):1270-7.

15. Klessinger S. Zygapophysial joint pain in post lumbar surgery syndrome. The efficacy of medial branch blocks and radiofrequency neurotomy. Pain Med. 2013;14(3):374-7.

16. Kornick C, Kramarich SS, Lamer TJ, Todd SB. Complications of lumbar facet radiofrequency denervation. Spine (Phila Pa 1976). 2004;29(12): 1352-4.

17. Leggett LE, Soril LJ, Lorenzetti DL, Noseworthy T, Steadman R, Tiwana S, et al. Radiofrequency ablation for chronic low back pain: a systematic review of randomized controlled trials. Pain Res Manag. 2014;19(5):e146-e153153.

18. Lee $\mathrm{CH}$, Chung $\mathrm{CK}$, Kim $\mathrm{CH}$. The efficacy of conventional radiofrequency denervation in patients with chronic low back pain originating from the facet joints: a meta-analysis of randomized controlled trials. Spine J. 2017;17(11):1770-80.

19. Lamer TJ, Smith J, Hoelzer BC, Mauck WD, Qu W, Gazelka HM. Safety of lumbar spine radiofrequency procedures in patients who have posterior spinal hardware. Pain Med. 2016;17(9):1634-7.

20. Lawrence BD, Wang J, Arnold PM, Hermsmeyer J, Norvell DC, Brodke DS. Predicting the risk of adjacent segment pathology after lumbar fusion: a systematic review. Spine (Phila Pa 1976). 2012;37(22 Suppl):S123-S132132.

21. Abd-Elsayed A, Fiala K, Nguyen S, VanderWood J. Safety and efficacy of radiofrequency ablation of the medial branch nerves with preexisting spinal hardware. A case series and review of literature. Curr Pain Headache Rep. 2019;23(2):11.

22. Gazelka HM, Welch TL, Nassr A, Lamer TJ. Safety of lumbar spine radiofrequency procedures in the presence of posterior pedicle screws: technical report of a cadaver study. Pain Med. 2015;16(5): 877-80.

23. Klessinger S. Safety and efficacy of lumbar spine radiofrequency neurotomy in the presence of posterior pedicle screws. Prog Orthop Sci. 2016;2(3): $30-4$. 
24. van Hecke O, Torrance N, Smith BH. Chronic pain epidemiology-where do lifestyle factors fit in? Br J Pain. 2013;7(4):209-17.

25. Institute of Medicine Committee on Advancing Pain Research C, Education. The National Academies Collection: Reports funded by National Institutes of Health. Relieving Pain in America: A Blueprint for Transforming Prevention, Care, Education, and Research. Washington (DC): National
Academies Press (US) National Academy of Sciences.; 2011.

26. Nath S, Nath CA, Pettersson K. Percutaneous lumbar zygapophysial (facet) joint neurotomy using radiofrequency current, in the management of chronic low back pain: a randomized double-blind trial. Spine (Phila Pa 1976). 2008;33(12):1291-7 (discussion 8). 